\title{
LO QUE EL GENOCIDIO NOS DEJÓ: CONSECUENCIAS JURÍDICAS Y PSICOSOCIALES EN LA RECUPERACIÓN DE LA NIÑEZ ROBADA EN ARGENTINA
}

\author{
Ana Laura Zavala Guillén ${ }^{1}$ \\ Lorena Ríos ${ }^{2}$ \\ Universidad Nacional de La Plata, Argentina \\ Ministerio Público Fiscal, Procuración General de la Nación
}

Resumen: La búsqueda de los niños apropiados por el aparato genocida, que se instauró en Argentina durante los años 1976 a 1983, continúa viva desde hace más treinta años. EI presente artículo reflexiona sobre las consecuencias jurídicas y psicosociales que los jóvenes recuperados han debido afrontar en el largo y sinuoso camino de vuelta a casa.

Palabras clave: genocidio, traslado forzado, niños, atención psicosocial, juicios

Abstract: The search for the children appropriated by the genocide apparatus, that established itself in Argentina from 1976 until 1983, has remained alive for over thirty years. This article represents a critical analysis of the legal and psychosocial consequences that those youth recovered from their appropriators have faced through the long and winding road back home.

Keywords: genocide, forcibly transferring children of the group to another group, children, psychosocial care, trials

Sumario.- A) Introducción: La apropiación como traslado forzado de niños de un grupo a otro grupo. B) La vuelta a casa: Historias con identidad propia. C) Atención integral de los niños y jóvenes cuya identidad fue restituida. D) Conclusiones.

Summary.- A) Introduction: appropriation as the forcibly transferring of children from one group to another group. B) The homecoming: stories with their own identity. C) Comprehensive care of children and youth whose identities were restored. D) Conclusion.

"Se acabó el miedo. El miedo se fue con María Sol. Yo soy Victoria".

Victoria Montenegro, hija de Hilda Torres y Roque Montenegro, desaparecidos.

\footnotetext{
1 Ana Laura Zavala Guillén, abogada egresada de la Universidad Nacional de La Plata (Argentina), Magister en Derechos Fundamentales por la Universidad Carlos III de Madrid (España), integrante de la Unidad Fiscal Federal especializada en la investigación de violaciones a los derechos humanos cometidas en la última dictadura militar argentina, Ministerio Público Fiscal, Procuración General de la Nación.

2 Lorena Ríos, abogada egresada de la Universidad Nacional de La Plata (Argentina), Maestranda de la Maestría de Derechos Humanos de la Universidad Nacional de La Plata, integrante de la Unidad Fiscal Federal especializada en la investigación de violaciones a los derechos humanos cometidas en la última dictadura militar argentina, Ministerio Público Fiscal, Procuración General de la Nación.
} 


\section{A) Introducción: La apropiación como traslado forzado de niños de un grupo a otro grupo}

¿Cómo describir la aniquilación y sus consecuencias? El debate acerca de cómo continuar después de Auschwitz y sus réplicas alrededor del mundo todavía se encuentra abierto. El escritor alemán Günter Grass entendió que Auschwitz es infinito cuando el pasado proyecta sus sombras sobre el presente y el futuro.

El genocidio también sucedió en la Argentina durante la década de los setenta. Mujeres y hombres hundidos en campos de exterminio, desaparecidos, con cuerpos marcados y sus niños robados para ser criados por aquellos que perpetraron las matanzas. Jóvenes que crecieron bajo otra identidad y que el impacto de la verdad ha causado también un Auschwitz personal que, en algunos casos, parece no tener fin. ¿Lo tendrá?

La maquinaria del horror puesta en marcha por la última dictadura cívico- militar argentina persiguió el aniquilamiento de una parte sustancial de la población nacional con la finalidad de "reorganizar" a la sociedad en su conjunto. Bajo esta lógica, los aniquiladores eligieron a sus víctimas no por su identidad personal considerada en sí misma, sino por su pertenencia o afinidad al grupo humano definido como enemigo a destruir ${ }^{3}$.

Como sostiene Daniel Feierstein, la dictadura argentina no sólo persiguió la eliminación de fuerzas políticas sino el exterminio de todas aquellas personas que representaban un "modo de construcción de identidad social" con la subsiguiente imposibilidad de pensar socialmente de esa manera ${ }^{4}$.

Esta afirmación no niega la existencia de víctimas "casuales", quienes desempeñaron un rol fundamental en la "diseminación del terror", demostrando que el poder de la dictadura era arbitrario y omnipresente. Todos podíamos ser potenciales desaparecidos. Dado que si bien el aniquilamiento físico tuvo como objetivo central la destrucción de las organizaciones políticas calificadas como "subversivas", la represión alcanzó a un conjunto muy amplio de personas directa o indirectamente vinculadas a los reprimidos, por ejemplo, familiares y amigos, haciendo sentir sus efectos al conjunto de estructuras sociales consideradas en sí como "subversivas por el nivel de infiltración del enemigo" (sindicatos, universidades, etc. $)^{5}$.

Obreros, maestras de escuela, estudiantes, librepensadores, activistas, catequistas tercer mundistas, abogados, periodistas, entre otros, formaron

\footnotetext{
${ }^{3}$ Alegato del Fiscal General Dr. Alejandro Alagia, en ocasión del juzgamiento de los crímenes de lesa humanidad cometidos en el circuito "Banco", "El Atlético" y "El Olimpo", de fecha 3 de noviembre de 2010.

4 (2007) FEIERSTEIN, Daniel, El genocidio como práctica social: Entre el nazismo y la experiencia argentina, Fondo de Cultura Económica de Argentina, Argentina, p. 53.

${ }^{5}$ (2006) CALVEIRO, Pilar, Poder y desaparición: Los campos de concentración en Argentina, EDICIONES COLIHUE SRL, Argentina, pp. 45-46.
} 
parte del grupo enemigo a aniquilar por los genocidas ${ }^{6}$. Las matanzas, las desapariciones forzadas, la tortura, la violencia sexual y las esterilizaciones forzadas, éstas últimas principalmente perpetradas contra las mujeres, constituyeron algunas de las prácticas llevadas adelante con dicho propósito.

Sin embargo, en este trabajo nos ocuparemos particularmente de una de las vulneraciones de la dignidad humana, que tuvo características propias y efectos insospechados hasta la actualidad: el traslado forzado de niños desde los grupos familiares de origen, opuestos ideológicamente al régimen, hacia los grupos familiares de los perpetradores o de personas afines con el sistema que la dictadura quería imponer y de moral occidental y cristiana ${ }^{7}$. Así, por ejemplo, la historia personal de Victoria Montenegro permite ilustrar lo antes descripto, dado que ella fue inscripta como María Sol, hija de Hérman Tetzlaff, jefe de tareas del centro clandestino de detención y torturas conocido como "El Vesubio" -quien luego de asesinar a sus padres- decidió apropiarse de la entonces niña para criarla "hecha y derecha" porque "genéticamente" era una "subversiva".

El propósito perseguido con el traslado forzado de niños quedó explicitado en las palabras de Ramón Camps, jefe de la Policía de la Provincia de Buenos Aires, quien manifestó en numerosas declaraciones ante la prensa, que si bien personalmente no había eliminado a ningún niño, había dado algunos a organizaciones benéficas para que les encontraran nuevos padres, dado que "los subversivos educan a sus hijos en la subversión" y esto debía detenerse.

Lo antes descripto quedó acreditado en el Informe de la Comisión Nacional sobre la Desaparición Forzada de Personas que estableció que durante la llamada "guerra sucia" existió un plan sistemático de apropiación de niños y desaparición de sus madres después del parto. Se estima que quinientos niños fueron desaparecidos junto con sus padres o nacieron o debieron nacer durante el cautiverio de sus madres 9 . Para esto, se dispusieron maternidades clandestinas que funcionaron en los centros de detención y tortura, sin perjuicio de que -en algunos casos- se utilizaron hospitales públicos para la atención de los partos de las mujeres secuestradas, evidenciándose la complicidad y el silencio de un sector de la sociedad civil ${ }^{10}$.

La clandestinidad de los alumbramientos no sólo suponía el secretismo sobre el lugar de permanencia de las embarazadas, desconocido para sus familiares,

\footnotetext{
${ }^{6}$ El "aniquilamiento" del grupo identificado como enemigo por los genocidas contó con un marco jurídico que le dio soporte a las diversas acciones ilegales desplegadas por las Fuerzas Armadas, las Fuerzas de Seguridad y el Personal Civil de Inteligencia. Para mayor información ver decretos $N^{\circ} 2770,2771$ y 2772 y directiva del Consejo de Defensa № 1/75 del año 1975 dictados durante la presidencia de María Estela Martínez de Perón.

${ }^{7}$ ESPAÑA, AUDIENCIA NACIONAL DE MADRID, JUZGADO CENTRAL DE INSTRUCCIÓN NÚMERO 5, Auto de dos de noviembre de mil novecientos noventa y nueve, Madrid.

${ }^{8}$ (2011) ABREVAYA DIOS, Mariano, "El robo de bebés en la dictadura entendido como plan sistemático", Miradas al Sur, Año 3, Edición $\mathrm{N}^{\circ}$ 146, Argentina, $<$ http://sur.elargentino.com/notas/el-robo-de-bebes-en-la-dictadura-entendido-como-plansistematico>

${ }^{9}$ (1985) COMISIÓN NACIONAL SOBRE LA DESAPARICIÓN DE PERSONAS, Nunca más: Informe de la Comisión Nacional sobre la desaparición de personas, Seix Barral, Barcelona, pp. 299-322.

${ }_{10}$ (2007) ABUELAS DE PLAZA DE MAYO, Maternidades Clandestinas, Pub. Electrónica de Abuelas de Plaza de Mayo, Argentina, <http://www.abuelas.org.ar/maternidades/>
} 
sino también prácticas que tenían como propósito castigar y quebrar a las mujeres en el momento del alumbramiento.

La advertencia bíblica "parirás con dolor" se hizo carne en las detenidas que daban a luz a sus niños, engrilletadas, desnudas frente a sus captores, insultadas entre risas y obligadas luego a limpiar la sangre que quedaba producto del nacimiento de sus hijos. Por ejemplo, Adriana Calvo, ex detenida desaparecida, relató que su parto se produjo mientras era trasladada de un centro clandestino de detención hacia otro. Así, dijo: "Teresa nació en el auto (...) ataron con un trapo que sacaron de la gaveta el cordón umbilical (...) Teresa estaba lógicamente unida a mí por el cordón umbilical. No me habían sacado la placenta (...) yo estaba con la manos atadas atrás y no la podía agarrar (...) iban muy rápido (...) y en algún momento se cayó entre los dos asientos y yo pedía por favor que me la alcanzaran, que la pusieran sobre mi panza y no lo hicieron (...) mientras me sacaban la placenta, mientras me hacían limpiar el piso (...) baldear, desnuda con Teresa llorando en la mesada de azulejos, todavía sucia... ellos se entretenían en insultarme"11.

En algunos casos, existieron lógicas aún más perversas, en los cuales las mujeres recibieron hermosos ajuares para el bautizo de sus niños y dieron instrucciones y escribieron cartas para que sean conducidos a sus familias, desconociendo el verdadero destino de sus niños y el suyo propio. Por ejemplo, en 1977, María Mercedes Molina Galarza nació durante el cautiverio de su madre Liliana Galarza, quien se encuentra desaparecida, en la Brigada de Investigaciones de la ciudad de La Plata. Su padrino de bautismo fue el Comisario de la dependencia policial, Luis Héctor Vides, su esposa proveyó el ajuar para la niña y la ceremonia fue oficiada por el sacerdote católico Christian Federico Von Wernich, quien fue condenado recientemente por la comisión de privaciones ilegales de la libertad, tormentos y homicidios de numerosas víctimas de la dictadura.

Sin embargo, la dictadura argentina no se conformó con el escarnio y la muerte de las mujeres. Así que una vez que los niños eran separados de sus madres, su traslado forzado se llevó adelante suprimiendo o eliminando la identidad de origen, a través de la falsedad ideológica de documentos públicos, verbigracia, certificado de nacimiento, acta de nacimiento y documento nacional de identidad, con los que se los inscribía como hijos de terceras personas, facilitando la retención y ocultamiento de los mismos de sus familias de origen.

Es importante destacar que la práctica descripta también se llevó adelante en otros contextos con dinámicas propias, como por ejemplo, en Australia, España y Guatemala.

En el caso de los niños indígenas australianos, durante el período colonial (1788-1901), con el fin de controlar la "amenaza aborigen", se llevaron a cabo políticas de separación y asimilación forzosa de estos

${ }^{11}$ Adriana Calvo falleció antes de que sus victimarios sean llevados a juicio. Testimonio brindado en el Juicio por la Verdad ante la Excma. Cámara Federal de la Ciudad de La Plata, con fecha 16/12/2000. 
niños de sus comunidades de origen para su reeducación o empleo como mano de obra ${ }^{12}$.

Asimismo, en España, durante la dictadura franquista, los llamados "niños perdidos" fueron hijos de presos republicanos, cuyos apellidos se modificaron para permitir su adopción por familias adictas al régimen. A diferencia de lo sucedido en nuestro país, la separación de los niños de sus padres se realizó sin clandestinidad y bajo el amparo de la normativa franquista. En algunos casos documentados, los niños fueron apropiados por militares españoles ${ }^{13}$.

También en Guatemala, principalmente entre los años 1979 y 1983, se llevaron adelante campañas de exterminio que recayeron especialmente sobre los pueblos originarios, ocurriendo también el traslado forzado de niños indígenas a los grupos pertenecientes a las fuerzas represivas ${ }^{14}$. De esta manera, el caso de Ana Choc, una niña desaparecida a los diez años, quien fue llevada por el jefe de las Patrullas de Autodefensa Civil y utilizada como sirvienta, refleja esta práctica. Según la afirmación del General Héctor Alejandro Gramajo, Ministro de Defensa de Guatemala durante el gobierno de Vinicio Cerezo e ideólogo de la Doctrina de la Estabilidad Nacional, "muchas de las familias de oficiales del Ejército han crecido con la adopción de niños víctimas de la violencia"15.

De esta manera podemos afirmar que la apropiación de niños inserta en planes de exterminio de grupos humanos constituye genocidio, en su forma específica, de traslado por fuerza de éstos de un grupo hacia otro grupo, sin perjuicio de que también implique la perpetración de crímenes de lesa humanidad en contextos de violaciones masivas y sistemáticas de los derechos fundamentales ${ }^{16}$.

${ }^{12}$ (2010) ROBINSON, Shirleene y PATEN, Jessica, "La cuestión del genocidio y la separación forzosa de niños aborígenes: El caso de Australia en la época colonial", Revista de Estudios sobre Genocidio, Centro de estudios sobre Genocidio de la Universidad Nacional de 3 de Febrero, ISSN 1851-8184, Vol. 4, p. 9.

${ }^{13}$ ESPAÑA, Audiencia Nacional de Madrid, Juzgado Central de Instrucción N 5 , Auto del 18 de noviembre de 2008.

${ }^{14}$ Un ejemplo de esta práctica en Guatemala es recogido en el Caso de la "Masacre de las Dos Erres vs. Guatemala" donde se relata, entre otras cosas, los hechos que damnificaron a Ramiro Osorio Cristales. Así, se determinó que "ha sido extensamente documentado que algunos niños fueron salvados de las masacres para ser "adoptados" por oficiales del ejército o llevados a sus hogares como sirvientes. Ejemplo de esta práctica es precisamente el caso del niño sobreviviente de la masacre de Las Dos Erres, Ramiro Fernando López García, cuyo nombre biológico es Ramiro Osorio Cristales, quien fue "adoptado" por uno de los soldados que participaron en los hechos". ORGANIZACIÓN DE ESTADOS AMERICANOS, CORTE INTERAMERICANA DE DERECHOS HUMANOS, Caso de la "Masacre de las Dos Erres vs. Guatemala", sentencia del 24 de noviembre de 2009, p. 162.

${ }^{15}$ (2002) OFICINA DE DERECHOS HUMANOS DEL ARZOBISPADO DE GUATEMALA, Hasta encontrarte. Niñez Desaparecida por el Conflicto Armado Interno en Guatemala, Guatemala, p. 53.

${ }^{16}$ El artículo 2 de la Convención para la Prevención y Sanción del delito de Genocidio establece que se entiende por "genocidio cualquiera de los actos mencionados a continuación, perpetrados con la intención de destruir total o parcialmente a un grupo nacional, étnico, racial o religioso como tal: a) Matanza de miembros del grupo; b) Lesión grave a la integridad física o mental de los miembros del grupo; c) Sometimiento intencional del grupo a condiciones de existencia que hayan de acarrear su destrucción física, total o parcial; d) Medidas destinadas a impedir los nacimientos en el seno del grupo; e) Traslado por fuerza de niños del grupo a otro grupo". NACIONES UNIDAS, Asamblea General, Convención para la Prevención y Sanción del 


\section{B) La vuelta a casa: Historias con identidad propia}

La búsqueda de los niños secuestrados por parte de sus familiares supervivientes comenzó a dar sus primeros frutos con la recuperación de la democracia en el año 1983.

Del análisis de los casos judiciales que se sometieron a estudio, se pudieron distinguir dos situaciones, por un lado, la de los niños desaparecidos que fueron localizados en su niñez, y por otro lado, la de aquellos que descubrieron su verdadero origen en su adultez.

En ambas situaciones, mientras unos plantean resistencias a conocer la verdad -por ejemplo, rechazando los exámenes genéticos identificatorios-, otros encuentran explicaciones a sus memorias y vivencias que le permiten encontrar otro nuevo punto de partida. Entonces, cuando la verdadera historia personal se revela, los ahora jóvenes apropiados deben afrontar múltiples consecuencias en términos jurídicos y psicosociales.

El retorno a la identidad de origen conlleva cambios de nombres y apellidos que deben ser registrados en sus documentos identificatorios, títulos profesionales y forma de ser llamados en sus entornos sociales ${ }^{17}$. Asimismo, mientras en algunos casos, la condena penal de quienes consideraban sus verdaderos padres es sentida como una reparación (en términos de justicia y verdad) en otros casos, la misma genera sentimientos de angustia y culpabilidad.

Constituye una verdad de perogrullo sostener que cada caso de apropiación es un mundo en sí mismo, y que por tanto, cada uno de ellos es merecedor de un análisis pormenorizado y particular, a partir del cual podemos arribar a conclusiones diversas. Sin embargo, compartiremos tan sólo algunas de las historias personales de los niños-jóvenes apropiados que consideramos paradigmáticas por su capacidad de abarcar a muchas otras.

\section{B. I. Historias personales de Elena Gallinari Abinet y de Gonzalo Javier y Matías Ángel Reggiardo Tolosa.}

En este apartado abordaremos las historias personales de Elena Gallinari Abinet y de Gonzalo Javier y Matías Ángel Reggiardo Tolosa cuyas identidades de origen fueron reveladas en su niñez con la consecuente restitución a sus familias biológicas.

La historia familiar de Elena comienza en el año 1973 cuando sus padres, Miguel Ángel Gallinari y María Leonor Abinet, conformaron una familia.

delito de Genocidio, aprobada el 9 de diciembre de 1948 por la III Asamblea general de las Naciones Unidas, $179^{a}$ sesión plenaria.

${ }^{17}$ En el año 2009, en la órbita del Ministerio de Justicia, Seguridad y Derechos Humanos, la Unidad de Regularización Documental de las Víctimas de Violaciones en el marco del accionar del Terrorismo de Estado que tiene como fin la asistencia a las víctimas de apropiación y/o sustitución de identidad en la obtención de la nueva documentación personal. ARGENTINA, PODER EJECUTIVO NACIONAL, MINISTERIO DE JUSTICIA, SEGURIDAD Y DERECHOS HUMANOS, Resolución 679/2009, Fecha de publicación: B.O. 02/10/2009. 
La militancia política y social de la pareja fue el motivo de su desaparición forzada y posterior ejecución extrajudicial, como mecanismos del terror empleados por el aparato represivo dispuesto por la última dictadura cívicomilitar.

Miguel Ángel Gallinari era delegado obrero y participaba en la Juventud Trabajadora Peronista y María Leonor Abinet era docente primaria, secundaria y universitaria, actuaba en asociaciones gremiales e integraba también dicha agrupación.

En marzo de 1976, María Leonor quedó embarazada de Elena, quien sería la única hija de la pareja.

En julio de dicho año, Miguel Ángel Gallinari fue secuestrado por primera vez en la localidad de Morón, Provincia de Buenos Aires. En esa ocasión, pudo escapar de su cautiverio mientras era trasladado de Campo de Mayo, centro clandestino de detención donde fue sometido a torturas y otros tratos crueles, inhumanos y degradantes. Debido a esta circunstancia, la pareja se vio obligada a itinerar por distintos domicilios ante la amenaza constante de ser objeto de nuevos secuestros.

Tiempo después, Miguel Ángel fue otra vez detenido ilegalmente y su cuerpo sin vida fue encontrado el día 21 de julio de 1976 en la localidad de Morón. Asimismo, el día 16 de septiembre del mencionado año, María Leonor, embarazada de siete meses, fue secuestrada en horas de la madrugada mientras se encontraba junto a sus hijas -de su primera pareja- en una pensión sita en la localidad de Caseros.

Los restos mortales de quien en vida fuera María Leonor Abinet fueron identificados en mayo de 2009, en el marco de la Iniciativa Latinoamericana para la Identificación de Personas Desaparecidas.

Hasta el presente, no se ha podido determinar con precisión el lugar donde permaneció cautiva María Leonor, como tampoco las circunstancias de su alumbramiento.

Con fecha 26 de marzo de 1987, la señora Leonor Isabel Alonso denunció la apropiación de su nieta, Elena Gallinari Abinet.

Como consecuencia de dicha denuncia, el 9 de abril de 1987 se realizó la pericia de histocompatibilidad en el Hospital General de Agudos Dr. Carlos G. Durand, cuyo resultado determinó el vínculo biológico de la niña (quien fuera conocida hasta ese momento como Nancy Viviana Madrid, ya que se encontraba inscripta como hija biológica de Domingo Luis Madrid y María Mercedes Elichalt) con las familias de los desaparecidos.

Domingo Luis Madrid desempeñó el cargo de Oficial Sub-inspector de Seguridad y posteriormente, Oficial Inspector en la Dirección de Investigaciones (Delitos contra la propiedad) Zona Metropolitana de la Policía de la Provincia de Buenos Aires ${ }^{18}$. En dicha dependencia policial funcionó, durante noviembre de 1974 y octubre de 1978, el centro de detenciones y torturas conocido como "Pozo de Banfield". Una de las particularidades de este

${ }^{18}$ Domingo Luis Madrid y María Mercedes Elichalt se encuentran actualmente procesados y a la espera del juicio oral por los hechos que damnificaron a Elena Gallinari Abinet. 
centro de exterminio de prisioneros fue la presencia notable de mujeres detenidas ilegalmente que se encontraban en estado de gravidez. Así, contaba con instalaciones para la realización de los partos clandestinos de dichas mujeres $^{19}$.

Luego de un proceso judicial, a la edad de 10 años, Elena Gallinari Abinet fue restituida a su familia biológica compuesta por sus abuelos y tíos maternos y paternos. Elena mostró comprensión y una aceptación rápida de los hechos revelados, dado que ella siempre supo que no era hija biológica de MadridElichalt, y por tanto, su incorporación a su familia de origen se llevó sin mayores sobresaltos ${ }^{20}$.

La historia de los mellizos Gonzalo Javier y Matías Ángel Reggiardo Tolosa guarda similitudes y diferencias con la historia de Elena Gallinari Abinet.

María Rosa Tolosa y Juan Enrique Reggiardo, padres de los mellizos, integraban la organización "Montoneros"21. Su militancia política y social ocasionó su secuestro y posterior desaparición forzada, que perdura hasta la actualidad.

María Rosa, tras el paso por distintos centros clandestinos de detención y tortura, dio a luz a los niños en la Unidad Penitenciaria de Lisandro Olmos, quienes fueron anotados como hijos biológicos del subcomisario Samuel Miara y su esposa Beatriz Castillo, bajo otra identidad, circunstancia que provocó la separación de sus familias de origen.

Samuel Miara, integrante de la Policía Federal Argentina, cometió crímenes de lesa humanidad en el circuito de detenciones y torturas conocido como "El Atlético", "Banco" y "El olimpo", según la condena a prisión perpetua dictada por el Tribunal Oral Federal N² de Capital Federal, en diciembre de 2010.

En el año 1986, tras una denuncia recibida en la Asociación Abuelas de Plaza de Mayo, se inició una investigación judicial mediante la cual el juez ordenó los análisis inmunogenéticos de los mellizos, medida que no se pudo llevar a cabo atento a que Miara, junto a su esposa y los niños, se fugaron del país.

En 1989, luego del trámite de extradición, al regresar los niños a la Argentina, se realizaron la pericia genética que confirmó que eran los hijos de María Rosa y Juan Enrique.

Años después, los mellizos quedaron bajo la custodia de su tío materno, pero tras múltiples conflictos familiares, permanecieron hasta la mayoría de edad con una familia substituta, para luego retomar vínculo con sus apropiadores.

${ }^{19}$ (2007) ASOCIACIÓN ABUELAS DE PLAZA DE MAYO, Maternidades clandestinas, op. cit.

20 ASOCIACIÓN ABUELAS DE PLAZA DE MAYO, Testimonios de Nietos, Pub. Electrónica de Abuelas de Plaza de Mayo, Argentina, $<$ http://www.abuelas.org.ar/areas.php?area=testimoniosNietos.php\&der1=der1_mat.php\&der2= der2_mat.php>

${ }^{21}$ Las organizaciones armadas peronistas incluían distintos agrupamientos guerrilleros entre ellos, "Montoneros", "Fuerzas Armadas Revolucionarias" (FAR), "Fuerzas Armadas Peronistas" (FAP) y "Descamisados". (2008) CALVEIRO, Pilar, Política y/o violencia: Una aproximación a la guerrilla de los años 70, Verticales de Bolsillo, Argentina, p. 74. 


\section{B. II. Historias personales de Eva Daniela Donda, Victoria Donda Pérez y Laura Ruiz Dameri}

En este apartado abordaremos las historias personales de Eva Daniela Donda Pérez, Victoria Donda Pérez y Laura Ruiz Dameri, cuyas identidades de origen fueron reveladas en su adultez, asumiendo distintas posiciones ante la verdad $^{22}$.

María Hilda Pérez y José María Laureano Donda, padres de Eva Daniela y Victoria, y Silvia Beatriz María Dameri y Orlando Antonio Ruiz, padres de Laura, quienes integraban la organización "Montoneros", fueron secuestrados y permanecen desaparecidos hasta la actualidad.

Ambas mujeres, tras el paso por distintos centros clandestinos de detención y tortura, dieron a luz a sus hijas, Victoria y Laura, en la maternidad clandestina de la Escuela de Mecánica de la Armada Argentina (ESMA), lugar donde cumplía funciones quien sería su apropiador, Juan Antonio Azic, ayudante mayor de la Prefectura Naval Argentina ${ }^{23}$. Arrebatadas de los brazos de sus madres, Victoria y Laura fueron inscriptas como hijas biológicas del matrimonio Azic, creciendo, bajo otra identidad, separadas de sus familias de origen.

Por su parte, Eva Daniela -quien tenía un año de vida cuando sus padres fueron secuestrados- creció junto a su tío paterno biológico Adolfo Donda Tigel, jefe de grupo de operaciones de la ESMA, quién no sólo no evitó la desaparición de su hermano José María Laureano Donda, sino que autorizó el asesinato de su cuñada María Hilda Pérez y la apropiación de su sobrina Victoria a manos de Azic ${ }^{24}$.

En el año 2003, la Asociación Abuelas de Plaza de Mayo recibió una denuncia que comunicaba sobre la posibilidad de que Juan Antonio Azic tuviera en su poder dos hijas de personas desaparecidas.

Tras un largo proceso judicial, mientras que Victoria -quien para ese entonces se llamaba Analía- aceptó realizarse los exámenes de ADN que permitieran determinar su identidad biológica, Laura llevó adelante una batalla legal para impedir la extracción de su sangre que finalmente, culminó en la obtención de muestras biológicas de objetos personales que facilitaron su identificación.

Es importante destacar, que tiempo atrás, ante la negativa de una joven de someterse a una extracción compulsiva de sangre que determinara su filiación biológica con víctimas de la dictadura, la Corte Suprema de Justicia de la Nación Argentina sentenció que existían límites a la búsqueda de justicia y

22 (2010) ABUELAS DE PLAZA DE MAYO, Niños desaparecidos, Jóvenes localizados 19752010, Pub. Electrónica de Abuelas de Plaza de Mayo, Argentina, <http://www.abuelas.org.ar/Libro2010/index_restituidos.php>

${ }^{23}$ La Escuela de Mecánica de la Armada (ESMA) fue una dependencia donde funcionó uno de los más grandes centros de detención y tortura que existieron en suelo argentino, en el cual permanecieron secuestradas más de cinco mil personas.

${ }^{24}$ En 1979, Adolfo Donda Tigel le manifestó a una detenida: "Esto es una guerra. Y en la guerra no se puede ser piadoso con el enemigo. No lo fui con mi propio hermano, que era monto. No lo fui con mi cuñada, que estuvo chupada como vos, acá, en la ESMA. Y fue trasladada como lo vas a ser vos también si no haces los deberes. No tuve ningún tipo de condescendencia ni culpa". (2004) GINZBERG, Victoria, "Donda fue el responsable directo", Página 12, <http://www.pagina12.com.ar/diario/elpais/1-42729-2004-10-24.html> 
verdad de los familiares de los desaparecidos que radicaban en el derecho a la intimidad de la joven que debía ser respetado. Sin embargo, los fundamentos de la Corte Suprema en la sentencia no lograron convencer a los tribunales inferiores, ya que éstos continuaron dictando medidas de prueba compulsivas para restablecer la identidad de los jóvenes presuntos hijos de desaparecidos. Estos órganos judiciales consideraron a los allanamientos de morada, que tenían por fin obtener objetos personales que contuvieran restos biológicos que permitieran realizar estudios de ADN, como la alternativa jurídica posible a las controvertidas extracciones compulsivas de sangre ${ }^{25}$. En 2009, la Corte Suprema declaró que estas medidas alternativas de prueba no vulneraban derechos fundamentales de los presuntos jóvenes apropiados, y que de esta manera, se garantizaban los valores superiores de la verdad y la justicia ${ }^{26}$.

En noviembre de 2009, la Ley Nacional $N^{\circ} 26.548$ dispuso que el Banco Nacional de Datos Genéticos, en el cual obran datos genéticos de los familiares de las personas desaparecidas, asesore a los jueces nacionales y federales en relación con el levantamiento de rastros forenses útiles para la obtención de información genética. Asimismo, la Ley Nacional N²6.549 estableció que cuando se requiera $A D N$ de la presunta víctima y ésta se opusiera a su extracción, el juez procederá a su obtención por medios alternativos a la inspección corporal con el fin de evitar su revictimización.

Es necesario señalar la posición pública que asumió Victoria al deslindar severamente el ámbito público de lo privado. Mientras que en su ámbito personal, sostiene que ha perdonado y continúa queriendo a sus apropiadores, asume que éstos deben ser juzgados y condenados por los crímenes que han cometido. Su impunidad no es admisible ${ }^{27}$. Decisión parcialmente contraria a la de aquellos hijos de desaparecidos que, ante la verdad develada, rompieron lazos con sus victimarios y los han llevado ante la justicia, acusándolos de haberlos privado de sus vínculos familiares de origen ${ }^{28}$. Mientras en la vereda de enfrente se encuentran aquellos jóvenes recuperados, quienes como Eva Daniela, rechazan a sus familias biológicas y defienden y justifican a ultranza a quienes consideran sus verdaderos padres, ante la ley sus apropiadores.

\section{Atención integral de los niños y jóvenes cuya identidad fue restituida}

La sustitución de identidad constituye un ataque directo al libre desarrollo de la personalidad. Esta situación se traduce en la vulneración de múltiples derechos

\footnotetext{
${ }^{25}$ (2009) ZAVALA GUILLÉN, Ana Laura, "Que mi cuerpo no sea utilizado en contra de mis victimarios: El caso "Vázquez Ferrá" y los límites a la búsqueda de justicia y verdad", Universitas, Revista de Filosofía, Política y Derecho, № 9, ISSN, 1698-7950, Madrid, pp. 21-44. ${ }^{26}$ ARGENTINA, CORTE SUPREMA DE JUSTICIA DE LA NACIÓN, "Gualtieri Rugnone de Prieto, Emma Elidia y otros s/ sustracción de menores de 10 años", 11 de agosto de 2009, considerando 15.

${ }^{27}$ (2010) SCHEJTAMAN, Natalí, "V de Victoria", Revista Rolling Stone, Año 13, Número 152, ISSN 0329-5656, Argentina, pp. 46-52.

${ }_{28}$ María Eugenia Sampallo Barragán, quién recuperó su identidad en el año 2001, fue querellante en el juicio contra sus apropiadores. (2008) PÁGINA 12, "La justicia sentenció a ocho y siete años de cárcel a los apropiadores de María Eugenia Sampallo: Una condena por "un vínculo cruel y perverso", <http://www.pagina12.com.ar/diario/elpais/1-101920-2008-0405.html>
} 
humanos reconocidos en instrumentos internacionales. A modo enumerativo, podemos enunciar: el derecho al nombre y las relaciones familiares de conformidad con la ley sin injerencias ilícitas, el derecho a la vida privada y familiar, entre otros.

Consideramos que la identidad debe ser entendida como un conjunto de múltiples y complejas facetas, entre las cuales podemos encontrar el llamado bagaje genético. Es claro que en los casos de apropiación de niños durante la última dictadura militar, la revelación del origen genético implica conocer una historia personal de sucesivas tragedias que también forma parte de la identidad de éstos ${ }^{29}$.

Para la sociedad civil, sólo la verdad y la justicia permitirían salir a la Argentina del período más oscuro de su historia. En el caso de los niños apropiados, el retorno a sus familias de origen era entendido como la única forma de reparación posible para ellos, para sus padres y familiares.

La búsqueda de los niños apropiados fue encabezada por la Asociación de Abuelas de Plaza de Mayo, organización fundada en octubre de 1977 por mujeres unidas por la pérdida de sus hijos y nietos.

Las primeras restituciones implicaron la participación de profesionales de diversos campos de la ciencia que asistieron a la justicia. Psicólogos y trabajadores sociales fueron piezas claves en la vuelta a casa de los niños y niñas. Las entrevistas mantenidas con éstos conllevaban al paulatino descubrimiento de la verdad. Asimismo, los informes ambientales evaluaban la manera más pertinente de la restitución del niño a su familia de origen.

Sin embargo, este proceso no fue siempre pacífico. Existieron casos en los cuáles los niños o los ahora jóvenes adultos mostraron resistencias a la aceptación de la verdad.

Esto conllevó a la creación de organismos especializados que permitieron un acompañamiento al individuo en la recuperación de parte de su historia personal. Por ejemplo, la Comisión Nacional por el Derecho a la Identidad (CONADI) y el Comité para la Defensa de la Salud, la Ética y los Derechos Humanos (CODESEDH).

La CONADI fue creada en el año 1992 a solicitud de la Asociación de Abuelas de Plaza de Mayo, quienes reclamaban al gobierno la creación de un organismo técnico especializado. La misma está integrada por representantes del Estado y de la Asociación Abuelas de Plaza de Mayo y su objetivo en un principio fue la búsqueda de niños desaparecidos durante la última dictadura cívico militar. Dicho objetivo se amplió por las denuncias recibidas por tráfico y robo de niños, al ser el único organismo especializado en el ámbito del Estado Nacional dedicado a la temática de garantizar el derecho a la identidad.

Por su parte, el CODESEDH es una asociación civil conformada por profesionales de distintas disciplinas, que posee entre otras áreas de trabajo, la asistencia a testigos víctimas en los juicios por crímenes de lesa humanidad. El equipo del CODESEDH, conformado por médicos, abogados, psicólogos, trabajadores sociales y agentes comunitarios, realizan un acompañamiento integral a la víctima, tanto legal, médico-psicológica y socio-familiar.

${ }^{29}$ (2009) ZAVALA GUILLÉN, Ana Laura, op. cit. 
Sin embargo, a pesar de la existencia de organismos que brindan acompañamiento psicosocial a las víctimas, queda al arbitrio y a la buena disposición de los operadores de la justicia, la intervención de los mismos en los procesos judiciales que se entablan a partir de las sospechas de que un joven puede ser hijo de personas desaparecidas, dado que la vuelta a casa de los niños y jóvenes apropiados no pudo ser entendida sin la condena de aquellos que fueron partícipes de su secuestro.

Fue así que en 1983, terminada la dictadura, el gobierno constitucional dispuso el juzgamiento de los máximos responsables de las violaciones a los derechos fundamentales cometidas, condenándolos por la comisión de privaciones ilegales de la libertad, homicidios y tormentos de cientos de víctimas. Las leyes de amnistía dictadas con posterioridad impidieron el juzgamiento de los mandos inferiores, brazos ejecutores de las torturas, desapariciones y matanzas. Sin embargo, es importante destacar que el secuestro de niños hijos de desaparecidos quedó por fuera de la normativa que aseguraba la impunidad de los perpetradores.

De esta manera, se llevaron adelante procesos judiciales penales que investigaron las apropiaciones de los niños, entendiendo a las mismas como delitos comunes, y por tanto, muchos de los juicios prescribieron por acción del tiempo, sin llegar a la condena de los apropiadores.

En 2005, la Corte Suprema de Justicia de la Nación declaró la inconstitucionalidad de las leyes de amnistía por vulnerar principios internacionales de derechos humanos. A partir de entonces, los asesinatos, los tormentos, las desapariciones y las apropiaciones de niños se comprendieron como crímenes de lesa humanidad y por tanto, imprescriptibles.

A la fecha, existen 32 condenados por la sustracción y suposición de la identidad de los hijos de desaparecidos, entre los cuales se encuentran los entregadores de los niños, sus apropiadores, médicos y parteras que falsificaron las constancias de nacimiento.

Para finalizar, consideramos que tomar en serio los derechos de los jóvenes apropiados requiere que el acompañamiento psicosocial en la vuelta a casa sea una política pública exigida por ley como lo son el juzgamiento de los genocidas y la protección de la seguridad de los testigos de los juicios que se llevan en la actualidad.

La estabilidad emocional y la protección de la integridad psicológica de las víctimas de apropiación poseen la misma importancia y trascendencia que la protección de la integridad física ante las amenazas de aquellos que continúan trabajando en las sombras de la impunidad.

La reforma de la ley 26.549 antes citada, que ha legitimado la toma compulsiva de muestras de ADN por medios alternativos, hubiera sido una oportunidad jurídica para receptar buenas prácticas de atención integral de víctimas de violaciones graves a los derechos humanos. Dado que los medios alternativos pueden, en algunos casos, contribuir a la no revictimización, pero no son suficientes si no se existe la posibilidad para la víctima de un acompañamiento psicosocial sin intereses en juego. 
Por tanto, la atención integral continúa siendo una deuda pendiente a saldar por el legislador, conforme lo exigen los compromisos internacionales asumidos por el Estado Argentino en materia de derechos humanos.

\section{Conclusiones}

Cuando el horror, aquello que no nos atrevemos a poner en palabras, sale a la luz, las sociedades se preguntan qué hacer con el legado de violaciones a los derechos humanos, cómo poner fin a la infinidad escalofriante de Auschwitz.

Los jóvenes que la democracia ha recuperado se encuentran recogiendo pedazos de historias incompletas, buscando explicaciones de lo inexplicable, aceptando que parte de sus vivencias se hunden en el silencio absoluto de los aniquiladores.

La reparación del daño sufrido no sólo implica garantizar el acceso a la justicia, la rehabilitación psicológica y física y las indemnizaciones pecuniarias correspondientes, sino el respeto y acompañamiento en los tiempos y contradicciones de los jóvenes apropiados, con el fin de no incrementar la victimización de la que mucha veces son objeto, una y otra vez, sin dejar de aspirar a la justicia y a la verdad de los hechos que enlutaron a nuestro país durante años ${ }^{30}$.

Tiempo antes de finalizar este trabajo, Victoria Montenegro, cuya historia personal hemos mencionado, prestó declaración ante el tribunal que juzga las apropiaciones de niños en el marco del centro clandestino de detención y tortura que funcionó en Campo de Mayo, dependencia del Ejército Argentino.

Nos parece oportuno entonces traer a colación sus palabras que muestran el camino para asumir el control de su vida arrebatada, dejar de vivir en el miedo y en la mentira.

Así, relató: "me siento tranquila, en paz (...) Herman no sólo fue el jefe del grupo de tareas, sino que fue la persona que asesina a mis padres y me lo cuenta (...) Tenía 25 años cuando me contó que no era hija suya. Yo me enteró después de que la justicia me da el ADN en el que se comprueba quiénes eran mis padres biológicos (...) Para mí todos tenían la culpa menos él: las Abuelas, mis padres biológicos, la historia, todos menos él. Hasta que llega un momento que se te cae el pañuelo y hay cosas que no se pueden seguir defendiendo. Pude incorporar a mis papás. Fue hace dos años. Me acuerdo que fue una Navidad. Por primera vez sentí que extrañaba a mi papá, Toti. Ahí pude correr a Herman del rol de papá y ponerlos a ellos, recuperar mi identidad y presentarme como Victoria (...) Todavía tengo muchas contradicciones. No puedo defender a mi apropiador. Antes lo defendía y decía que la apropiación era un acto de amor. Hoy no (...) Mis abuelos se murieron buscándome. Ellos

30 NACIONES UNIDAS, ASAMBLEA GENERAL, Principios y directrices básicos sobre el derecho de las víctimas de violaciones manifiestas de las normas internacionales de derechos humanos y de violaciones graves del derecho internacional humanitario a interponer recursos y obtener reparaciones, Resolución n 60/147 aprobada por la Asamblea General con fecha 16 de diciembre de 2005 
[por los apropiadores] pudieron haberles dado a mis abuelos la oportunidad de verme y no me la dieron. El amor no hace eso"31.

La voz de Victoria parece señalar el camino ante situaciones que escapan a toda fecunda imaginación de laboratorio de $\operatorname{casos}^{32}$. Es así que como profesionales tenemos el desafío de cuestionar permanentemente las recetas del pasado en el tratamiento particular de cada caso en el que se debate el derecho a la identidad de un joven hijo de desaparecidos. No existen fórmulas seguras sobre las que podamos apoyarnos, sólo el triste consuelo de pensar que trabajamos para el futuro, para la no repetición de los hechos que pertenecieron a una época que -como sostuvo el escritor argentino Jorge Luis Borges- nunca podremos entender.

31 Para escuchar la entrevista de Victoria Montenegro: <http://www.continental.com.ar/nota.aspx?id=1460206>

${ }^{32}$ En ocasión de una negativa de un joven, presunto hijo de personas desaparecidas, a realizarse exámenes que permitan su identificación, aludiendo, entre varias razones, al derecho a no ser nuevamente victimizado aunque el reconocimiento de este derecho en plenitud implicaría la condena a seguir sufriendo una victimización producto de su apropiación, los Jueces Dres. Lorenzetti y Zaffaroni de la Corte Suprema de Justicia de la Nación sostuvieron: "Semejante paradoja es de tal magnitud que escapa a toda posible imaginación de laboratorio de casos, al punto de no existir doctrina ni jurisprudencia aplicable". ARGENTINA, CORTE SUPREMA DE JUSTICIA DE LA NACIÓN ARGENTINA, Voto particular de los señores magistrados Ricardo Luis Lorenzetti y E. Raúl Zaffaroni en "G. 291. XLIII. Gualtieri Rugnone de Prieto, Emma Elidia y otros s/ sustracción de menores de 10 años", 11 de agosto de 2009. 